
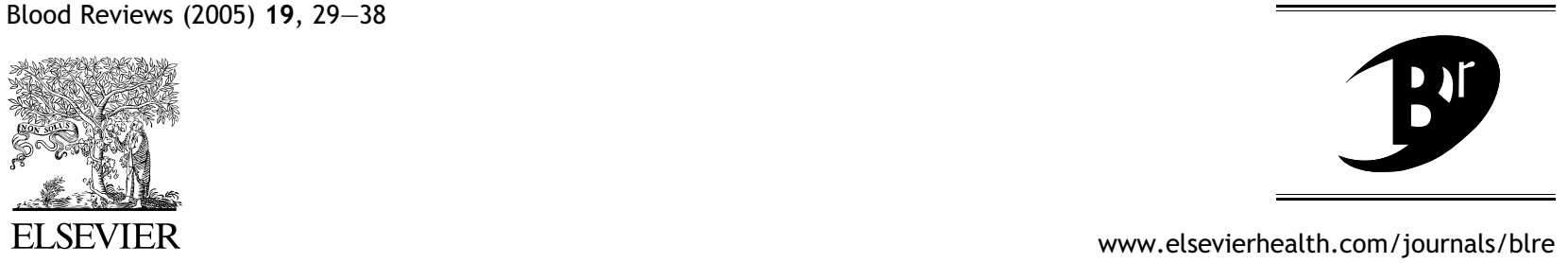

\title{
REVIEW
}

\section{Stem cell plasticity}

\section{Uma Lakshmipathy, Catherine Verfaillie*}

\author{
Stem Cell Institute, Hematology, Oncology and Transplantation Division, Department of Medicine, \\ University of Minnesota, 420 Delaware Street, Minneapolis, MN 55455, USA
}

\section{KEYWORDS}

Adult stem cells; Bone marrow-derived stem cells; Organ-derived stem cells; Plasticity; Mechanism of plasticity

\begin{abstract}
Summary The central dogma in stem cell biology has been that cells isolated from a particular tissue can renew and differentiate into lineages of the tissue it resides in. Several studies have challenged this idea by demonstrating that tissue specific cell have considerable plasticity and can cross-lineage restriction boundary and give rise to cell types of other lineages. However, the lack of a clear definition for plasticity has led to confusion with several reports failing to demonstrate that a single cell can indeed differentiate into multiple lineages at significant levels. Further, differences between results obtained in different labs has cast doubt on some results and several studies still await independent confirmation. In this review, we critically evaluate studies that report stem cell plasticity using three rigid criteria to define stem cell plasticity; differentiation of a single cell into multiple cell lineages, functionality of differentiated cells in vitro and in vivo, robust and persistent engraft of transplanted cells.
\end{abstract}

(c) 2004 Elsevier Ltd. All rights reserved.

\section{Introduction}

A stem cell is defined by three main criteria: selfrenewal, ability to differentiate into multiple cell types, and ability of in vivo reconstitution of a given tissue. A fertilized egg is capable of not only forming cells of the mesoderm, endoderm and ectoderm layer, and germ cells, but also the supporting trophoblast required for the survival of the developing embryo. These cells are therefore at the top of the hierarchy of stem cells and termed 'totipotent'. Embryonic stem (ES) cells and embryonic germ (EG) cells, isolated from the inner cell mass of the blastocyst or from primordial germ cells of an early embryo, give rise to mesoderm, endoderm, ectoderm and germ cells but not extra-embryonic tissues, and are therefore termed 'pluripotent'.

Corresponding author. Tel.: +1-612-625-0602.

E-mail address: verfa001@umn.edu (C. Verfaillie).
Stem cells isolated from various adult organs selfrenew and differentiate into multiple organ specific cell types are termed 'multipotent stem cells'. Committed cells that have limited or no selfrenewal ability and differentiate into only one defined cell type are termed 'progenitor cells' or 'precursor cells'.

\section{Adult stem cells and plasticity}

Traditionally, adult stem cells have been viewed as committed to a particular cell fate to produce cells from the tissue of origin but not cells of nonrelated tissues. For example, neural stem cells (NSCs) give rise to the three main types of nerve cells present in adult brain, hematopoietic stem cells (HSCs) produce blood, etc. Various reports over the last six years challenge this central dogma by demonstrating that adult stem cells, under 
certain microenvironmental conditions, give rise to cell types besides the cell type in the tissue of origin possibly indicating that they can switch cell fate. For example, HSC besides forming blood cells, have been reported to give rise to liver cells ${ }^{1}$ and NSC may not only give rise to nerve cells but also give rise to early hematopoeitic precursors. ${ }^{2}$ These observations have been termed "stem cell plasticity". Reports of stem cell plasticity have generated both excitement as well as skepticism ${ }^{3-7}$ in the field of stem cell biology, as the concept of plasticity defies developmental biology principles of lineage restriction being imparted during morphogenesis, but, if correct, the ability of adult stem cells to change fate also holds immense therapeutic potential. It is therefore important that the concept of stem cell plasticity be rigorously defined and experimentally proven. Unfortunately, until now, most studies have not shown that unexpected lineage differentiation is derived from the same single cell that differentiates to the expected cell type, and even when this was done the apparent lineage switch seen occurs in general at a very low frequency. Furthermore, the criteria used to establish plasticity in most of the studies has relied on morphology and immunostaining and seldom function. In most instances differentiation has depended on demonstration of co-expression of markers in the transplanted stem cells, such as the $Y$ chromosome, GFP or $\beta$-gal, and a particular antigen on the differentiated cell type, an approach that can be fraught with technical problems. ${ }^{8} \mathrm{Im}$ portantly, most plasticity studies still await independent confirmation from other researchers. Much of these problems arise from the fact that no clear parameters have been established to demonstrate or refute stem cell plasticity. In this review, we will use three main criteria for stem cell plasticity (box 1), based on which, reports of stem cell plasticity will be critically examined.

Box 1. Criteria defining stem cell plasticity

- A single cell differentiate into multiple cell lineages

- Differentiated cells are functional in vitro and in vivo

- Engraftment is robust and persistent

\section{Bone marrow-derived stem cells (BMDSC)}

The best-studied adult stem cell, the HSC, resides in adult life in the bone marrow (BM). ${ }^{9}$ Presence of HSC is demonstrated by the ability of transplanted donor cells to reconstitute the hematopoietic system of a lethally myeloablated host. Murine HSC reside in the lineage negative fraction of cells, and express the stem cell antigens Sca1, and low levels of cKit and Thy1. In humans, HSC are also lineage negative and further enriched in the CD34+CD38subpopulation, In mouse and man, HSC can be enriched based on the fact that they express the ABCG2 transporter and thereby exclude Hoechst dye; such cell are termed SP (side-population). Aside from HSC, several other stem cells exist in bone marrow. These include mesenchymal stem cells (MSC). MSC can be isolated from $B M,{ }^{10}$ as well as adipose tissue ${ }^{11}$ and fetal lung. ${ }^{12}$ They lack the hematopoeitic surface marker, CD45, but in humans express CD105 (SH2), SH3, Stro-1 and CD13. MSC can be expanded ex vivo for 20-50 population doublings, differentiate into osteoblast, adipocytes and chondroblasts, as well as smooth muscle and skeletal muscle cells, and engraft in vivo at low level in multiple tissues. ${ }^{13} \mathrm{BM}$ also is the source of endothelial progenitor cells (EPC). These cells can be expanded for prolonged periods of time in vitro, and can be recruited to areas of injury contributing to vasculogenesis in post-natal life. There is, at least in mice, also evidence that a precursor for EPC may exit in BM, namely the hemangioblast, a cell initially characterized in ES cell cultures that can give rise to HSC, EPC and smooth muscle cells. ${ }^{14-18}$ Finally, others and we have shown that a rare cell type can be culture isolated from BM and other organs such as brain and muscle, termed multipotent adult progenitor cell or MAPC. MAPC can be expanded in culture for extended periods of time and differentiate into endothelium, endodermal and neural lineages in vitro and in vivo. ${ }^{19-21}$ How MAPC relate to MSC, and whether MAPC exist in vivo, or are induced during the extensive in vitro culture period is still unknown.

\section{BMDSC to mesoderm}

Osteoblast, chondroblast, adipocyte. The cell in $\mathrm{BM}$ that gives rise to bone, cartilage and fat is the MSC that can clonally differentiate in all three lineages. In humans, MSC have been isolated from $B M$ using a number of different cell surface markers, including $\mathrm{SH} 2$ and $\mathrm{SH} 3,{ }^{22,23}$ or VCAM and Stro1. ${ }^{24}$ Several studies have shown that differentiation not only occurs in vitro, but that MSC can contribute to cartilage, bone and muscle when transplanted in utero, ${ }^{25}$ or in fractures ${ }^{26}$ or articular defects ${ }^{27}$ post-natally. More recently, studies have suggested that cells with hematopoietic as well as in vivo osteoblastic potential may exist, and can be purified from murine BM based on a SP phenotype. ${ }^{28}$ How this population relates to MSC is 
not yet known. Other cell populations such as the mesangioblast defined by Cossu and Bianco, ${ }^{29}$ initially in the aortogonadmesonephros region, but also present in BM, as well as MAPC, ${ }^{19,21}$ differentiate into all mesenchymal lineage cells. Obviously the ability of MSC, or more pluripotent BMDSC to differentiate into mesenchymal lineage cells should not be considered plasticity.

Skeletal muscle. First evidence for contribution of BM cells to skeletal muscle came from studies by Ferrari et al., ${ }^{30}$ in which non-purified BM-MNC transplanted into immunodeficient mice were shown to migrate to areas of muscle degeneration where they contributed to regeneration of the damaged fibers. Subsequent studies showed that transplantation of enriched HSC into irradiated $\mathrm{mdx}$ mice, that have increased muscle cell turnover, leads to low level contribution to muscle and partial restoration of dystrophin expression in the affected muscle. ${ }^{31}$ Whether this occurs via simple fusion of HSC or other BM-derived cells with the muscle fiber, or via initial commitment of HSC to muscle satellite cells followed by fusion with muscle fibers is currently not yet clear. One study provides evidence for a stepwise progression of BM cells - which may be different from HSC as the cells were not purified - to satellite cell, the mononucleated muscle stem cell, and then to multinucleated myofibers, ${ }^{32}$ whereas such a progression could not be demonstrated in an other study, where it was believed that HSC differentiate first to mature myeloid cells that fuse with myofibers, but that HSC do not contribute to the satellite compartment. ${ }^{33}$ Differences in outcome between these studies may indicate that the cell in the first study responsible for contribution to the muscle compartment is not an HSC. MSC differentiate at least in vitro into skeletal muscle myoblasts. ${ }^{34}$ Likewise, the mesangioblast differentiates into skeletal muscle cells in vitro, and Sampaolesi and colleagues also showed robust contribution of these cells to muscle in vivo, following intraarterial injection into an animal model of muscular dystrophy due to lack of the $\alpha$-sarcoglycan gene. ${ }^{35}$ Finally, MAPC differentiate in skeletal muscle myoblasts in vitro ${ }^{19,21}$ and may contribute to skeletal muscle when injected in vivo. Whether engraftment of mesangioblasts or MAPC in muscle occurs via differentiation first into satellite cells or via direct fusion with muscle fibers was not addressed in these studies.

Cardiomyocytes. A number of studies have suggested that cells from BM may differentiate in vivo or in vitro in cardiac muscle. Bittner et al. ${ }^{36}$ showed that following transplantation of BM cells into mdx mice, some cardiac muscle cells appeared to be donor in origin and expressed dystrophin. Rat MSC appeared to form cardiomyocytes or fibroblasts upon injection in an infarct, depending on the specific microenvironment. ${ }^{37}$ Likewise, human MSC injected into the left ventricle of a SCID/beige mouse appeared to acquire cardiomyocyte features, ${ }^{38}$ and human MSC transplanted in fetal sheep could be detected in the heart where they acquired again some features of cardiomyocytes. ${ }^{39}$ All these studies depended solely on morphological and limited phenotypic characteristics to define the donor cells in the heart as cardiomyocytes. Moreover, levels of engraftment were usually very low. Other studies have shown that transplantation of BM-derived cells into the heart may result in functional improvement. Tomita et al. ${ }^{40}$ showed that transplantation of rat BM cells cultured and differentiated into cardiac-like muscle cells in vitro into a cryoinfact might improve cardiac function. Orlic et al. ${ }^{41,42}$ showed that transplantation of LincKit+ GFP+ BM cells into an infracted mouse heart results in large numbers of cardiac muscle-like cells in the infarct and significant functional improvement. However, several other studies using similarly selected cell populations could only detect low levels of engraftment or functional improvement. In one study, low numbers of donor cells could be detected in a myocardial infarct following systemic infusion of Sp cells in lethally irradiated animals. ${ }^{43}$ None of the studies have shown that the cardiomyocyte-like cells detected in vivo have electrophysiological characteristics of cardiac muscle cells, and are linked via connexins with the surrounding heart tissue, as has been shown for fetal cardiomyocytes and ES-cell derived murine cardiomyocytes. ${ }^{44,45}$ In addition, none of the studies addressed the question whether differentiation was direct differentiation of a BM stem cell or fusion of a BM-derived cell with existing cardiac muscle cells. Finally, a single paper has shown in vitro that an MSC cell line from mouse could be induced to differentiate to rhythmically contracting cells, with cardiac muscle markers, and electrophysiological characteristics of cardiomyocytes. ${ }^{46}$ Whether this is unique to this single MSC cell line, or most MSC can differentiate to cardiac myoblasts in vitro still needs to be determined.

Endothelium. The final mesodermal lineage that can be generated by BM-derived stem cells is endothelium. Recent studies have suggested that endothelial "stem cells" may persist into adult life, where they contribute to the formation of new 
blood vessels, ${ }^{47}$ suggesting that like during development neoangiogenesis in the adult may at least in part depend on a process of vasculogenesis. Precursors for endothelial cells have been isolated from $B M$ and peripheral blood. ${ }^{48,49}$ So, it may not be that surprising that a number of studies have shown that transplantation of non-purified BM cells leads to contribution of donor cells to vascular beds. During development, endothelial progenitors and $\mathrm{HSC}$ are derived from a common ancestor, the hemangioblast that can be purified from the AGM region $^{50}$ and can be selected based on expression of the VEGF receptor 2, Flk1, from differentiating embryoid bodies in vitro. ${ }^{51}$ Until recent there was no evidence that hemangioblasts may persist in adult life. However, a recent study by Grant et al. ${ }^{15}$ showed that following transplantation of a single HSC in lethally irradiated mice, endothelial cells in the retina - following vascular injury - were in part derived from the progeny of the single HSC. Whether this could be explained by fusion was not addressed. Similar cells may also be present in human BM and human umbilical cord. ${ }^{52,53}$ In addition, the mesangioblast and MAPC also form endothelium in vitro and in vivo. Thus, like during development, multipotent stem cells that can differentiate not only into endothelium but also other cell types may persist. Again, one would not necessarily classify this as plasticity.

\section{BMDSC to neuroectoderm}

Several reports have presented evidence that BM cells may generate various cell types in the adult brain. Developmentally, neurons, astrocytes and oligodendrocytes are derived from NSC and microglial cells are derived from HSC. The first study reporting that $B M$ cells contribute to brain was by Eglitis and Mezey, ${ }^{54}$ in which female murine recipients transplanted with eGFP positive male BM showed a continuing influx of GFP+ male cells into the brain where they differentiated not only into microglia but also astrocytes. Further, evidence to support this was provided by a study where genetically marked mouse BM cells injected into irradiated normal hosts resulted in donor cells expressing neuronal markers such as NeuN and $\beta$ tubulin-III in brain sections. ${ }^{55} \mathrm{GFP}+$ mouse enriched HSC contributed to Purkinje neurons ${ }^{56}$ aside from microglial engraftment in the CNS of damaged mice. ${ }^{57} \mathrm{HSCs}$ were also shown to contribute to the functional recovery of hindlimb motor function in a spinal cord injury mouse model. ${ }^{58}$ Post-mortem brain samples from humans who underwent sex mismatched $B M$ transplants revealed the presence of what appeared to be donor-derived neurons..$^{59,60}$ While these studies suggest plasticity based on co- expression of the donor marker and neural tissue specific markers, clonality and functionality of the transdifferentiated cells was not addressed. Further, doubt has been cast on these claims by a number of studies that failed to reproduce the above results and found only minimal evidence of HSC contribution to neurons in the CNS. ${ }^{61,62}$

Other studies have presented evidence that BM MSC may contribute to the brain. Woodbury et al. ${ }^{63}$ presented evidence that MSC from rat and human $B M$ can differentiate into neurons in vitro using morphologic and phenotypic but not functional characterization. Other studies have suggested that murine or rat MSC may differentiate into cells with neuroectodermal characteristics in vivo. ${ }^{64,65}$ In two disease models, BM MSC supported at least partial correction of the disorder. These included improvement of demyelination in a demyelinating spinal cord disorder, ${ }^{66}$ and decreased loss of purkinje cells in an animal model of Niemann-Pick disease. ${ }^{67}$ Although at least partial functional recovery was observed, these studies did not prove that the MSC themselves contributed to the Schwan cell compartment or Purkinje cell compartment, and effects could be mediated via trophic factors produced by the MSC.

MAPC differentiate in vitro in response to sequential addition of cytokines thought to be involved in mid brain development, into neuroectodermal cells such as dopaminergic-like neurons. Such differentiation occurs in what appears a developmentally correct fashion, similar to ES cells and NSC. ${ }^{20,68}$ These experiments were carried out using clonally derived cells, which also differentiate into endothelium and hepatocyte-like cells, and expression of multiple neuronal markers and in vitro functional studies were used to prove neural differentiation. However, functional reconstitution of the in vivo CNS compartment by MAPC was not addressed.

\section{BMDSC to endoderm}

Several studies have also suggested that cells from BM may be capable of differentiating onto epithelial cells. For instance Krause et al. ${ }^{69}$ showed that a single HSC not only restores the hematopoeitic system but that HSC-derived cells could be found at variable frequencies $(1-15 \%)$ in the epithelia of the liver, lung, GI tract and skin, where they acquired tissue specific phenotypic characteristics. Other studies have, however, suggested that although such a phenomenon may be correct, the frequency of such an event may be very low $(1 / 100,000$ cells). Mature hepatocytes can undergo several cell divisions and are responsible for hepatic cell replacement. During extensive liver necrosis due to 
chemical injury or when hepatocytes are treated with chemicals that block their proliferation, a population of smaller cells with oval shape, termed oval cells, emerges and proliferates. ${ }^{70,71}$ These oval cells may constitute the "stem cell" compartment in the liver. Recent studies suggest that non-endodermal cells may also form hepatocytes in vivo and in vitro. ${ }^{23,69,72,73} \mathrm{~A}$ significant number of studies have studied the generation of liver cells from BM cells. Following $B M$ transplantation, oval cells are derived from the donor BM. ${ }^{1}$ However, other studies have not been able to confirm this notion. ${ }^{74}$ Transplantation of enriched HSC in FAH-/- mice, an animal model of tyrosenimia type I, resulted in the proliferation of large numbers of donor $\mathrm{LacZ}^{+}$ hepatocytes and animals had restored biochemical function of the liver, ${ }^{73}$ which was seen as proof for stem cell plasticity. Donor-derived cells in the liver with hepatocyte characteristics have also been detected in patients who received BM transplantations, and host-derived cells with hepatocyte markers in patients that underwent sex mismatched cadaver liver transplants. ${ }^{75,76} \mathrm{~A}$ rare population of human hematopoeitic cells that are lin-, CD45+, CD38-, CD34+/- and C1qR (p)+ may differentiate into hepatocytes when injected into mouse NOD-SCID mice. ${ }^{77}$ Finally, human, rat and mouse MAPC can differentiate in vitro in cells with phenotypic, morphological and functional characteristics of hepatocytes. ${ }^{78}$ In vivo studies demonstrating functional liver repopulation with MAPC are still lacking.

Two independent studies also show contribution of BM-derived cells to pancreatic islet cell regeneration. Following transplantation of BM cells from male mice that express eGFP (if the insulin gene is actively transcribed) into female recipient mice, 1.7-3\% GFP+, insulin+ donor cell could be detected in the pancreas. ${ }^{79}$ However, other studies suggested that although donor cells can be detected in the pancreas, they might be endothelial and not endocrine cells. For instance, in one study BM transplantation led to normalized levels of glucose and insulin in streptozotocin-induced diabetic mice even before donor-derived cells were detected in the pancreas thereby suggesting an indirect contribution of the BM cells to insulin production in the streptozotocin-treated mice. ${ }^{80}$

\section{Neural stem cells}

Isolated from fetal and adult brain, NSC proliferates and gives rise to all the major cell types of the central nervous system. ${ }^{81-83}$ There are reports suggesting that NSC can give rise to cells other than neural cells. One study demonstrated that clonally derived NSC could reconstitute the hematopoietic system following transplantation in lethally irradiated mice. ${ }^{2}$ However, a second study failed to reproduce these results, ${ }^{84}$ the reasons for which are not clear. Murine and human NSC may generate myoblasts when transplanted into muscle, ${ }^{85}$ and may generate smooth muscle myoblasts in vitro. ${ }^{86}$ Clarke et al. ${ }^{87}$ showed that injection of clonally derived NSC into chick embryos or murine blastocysts leads to the incorporation of NSC-derived progeny in multiple tissues, even though no live mice were obtained, and chimerism was not balanced.

\section{Epidermal stem cells}

Epidermis of the skin is known to contain a population of basal cells that exhibit properties typical of somatic stem cells. ${ }^{88}$ Adult hair follicles also contain multipotent stem cells that regenerate a wounded epidermis. ${ }^{89}$ These cells differentiate into epidermis, hair follicle sand sebaceous glands. ${ }^{90}$ Recently, a combination of Hoechst 33342-dye exclusion and hematopoietic lineage negative selection strategy has lead to purification of epidermal stem cells to near homogeneity. ${ }^{91}$ When injected into a developing blastocyst, such epidermal stem cells contributed to ectodermal, mesenchymal and neural crest-derived tissue. ${ }^{92}$ An other apparently multipotent adult stem cell can be derived from the dermis of fetal and adult rodent skin, and from human scalp, termed skinderived progenitors or SKPs. SKPs differentiate into neurons, glia, as well as smooth muscle cells and mesenchymal lineage cells (osteoblasts and adipocytes) in vitro, ${ }^{93}$ and are thought to potentially represent remnant neural crest stem cells.

\section{Muscle stem cells}

A number of different cells with stem cell properties have been identified in skeletal muscle, the best characterized of which is the muscle satellite cell. Satellite cells are myogenic stem cells, present between the muscle fibers and the basal lamina. ${ }^{94}$ They can be identified based on expression of the transcription factor Myf5 ${ }^{95}$ and are normally quiescent. ${ }^{96}$ Upon activation as a result of for instance muscle injury, satellite cells self-renew to repopulate the satellite cell pool and give rise to myoblasts. ${ }^{95,97,98}$ More recently, stem cells have also been isolated from muscle based on cell surface markers (Sca1, cKit, etc.) and their ability to exclude the Hoechst dye (SP phenotype) CD34+ 
Sca1+ muscle-derived cells can engraft in muscle and restore dystrophin expression in $\mathrm{mdx}$ mice. ${ }^{99}$ Asakura et al. ${ }^{100}$ showed that the muscle SP fraction might contain cells competent to form hematopoeitic colonies, as well as giving rise to skeletal muscle myocytes and satellite cells following intramuscular transplantation.

\section{Mechanisms of stem cell plasticity}

What mechanism underlies the apparent greater potency of adult stem cells, termed plasticity, is the subject of ongoing and very lively debates in the scientific community. Several possible mechanisms may underlie the apparent plasticity.

The most obvious explanation might be that, as a number of the reports were based on infusion of non-purified populations of cells, co-infusion of multiple different stem cells accounts for the engraftment in multiple tissues. Indeed, skeletal muscle contains HSC. For instance, infusion of nonpurified populations of muscle cells can repopulate the hematopoietic system at least in part because of the existence of HSC in the inoculum. ${ }^{101}$ This obviously does not constitute stem cell plasticity. However, as alluded to above, the possibility exists that SP cells in muscle may be bi-potent, i.e. give rise to muscle as well as hematopoietic cells. ${ }^{100}$

In lower animal species, such as in planaria, asexual multiplication occurs through the existence of pluripotent stem cells that can regenerate all tissues. Apparent plasticity could thus be due to persistence of similar more pluripotent stem cells in post-natal life. As discussed above, there may be evidence for persistence of cells with greater potency in mammals: for instance mesangioblasts, SKPs, MAPC, NSC and epidermal stem cells may be capable of differentiating into multiple different tissues outside of the tissue of origin. One caveat is that most of these cells have shown such potential following ex vivo culture, a process that may have caused de-differentiation. Studies will therefore be needed to demonstrate that such cells exist in vivo and the greater potency is not culture-induced. If such cells would be present in vivo, then again this would not represent plasticity, but merely remnant more multi or even pluripotent stem cells.

A third explanation for plasticity, representing true plasticity, would be de-differentiation and redifferentiation or even transdifferentiation. In such a process the nuclei of the transplanted cell would have undergone reprogramming to efface to some extent existing genetic information and acquiring new expressed genes and proteins consis- tent with the novel lineage. Again, there is evidence in nature that such phenomenon can occur. For instance in young newts in which a limb is removed, cells in the blastema undergo de-differentiation and then redifferentiate to make most cell types of the regenerating limb. ${ }^{102}$ Obviously, the process of cloning, in which the nucleus of an adult somatic cell is introduced in the cytosol of an unfertilized egg to recreate a whole animal exploits a similar phenomenon. ${ }^{103}$ Currently, there is no good proof as to whether plasticity seen in vitro or in vivo can be ascribed to this phenomenon. As mentioned above, it is possible that the isolation of what appear to be more pluripotent adult stem cells, such as MAPC, certain NSC, epidermal stem cells and mesangioblasts - which requires in general ex vivo culture - is the result of de-differentiation of more classical HSC, EPC, NSC or MSC.

A final explanation is that cell fusion occurs. Cell fusion is an old biological phenomenon and has been exploited extensively in the generation of hybridomas. ${ }^{104}$ That this process may underlie at least some of the observations of stem cell plasticity was first demonstrated by co-culture of genetically marked ES cells with genetically marked NSC or BM cells wherein the fused tetraploid cells retained the genetic marker expressed in the neural or BM cells, as well as the pluripotency of the ES cells. ${ }^{105,106}$ Since these initial in vitro reports, a number of in vivo studies have shown that fusion may also underlie the apparent lineage switch of HSC and BM grafts. For instance, follow-up studies to the initial report in which $F A H-/$ - animals were rescued from fatal liver failure by transplantation of enriched $\mathrm{HSC},{ }^{73}$ have shown that the liver nodules proliferate from tertraploid cells generated by fusion between HSC-derived cells and hepatocytes. ${ }^{72}$ Transplantation GFP+Cre+ BM cells into lethally irradiated $\mathrm{R} 26 \mathrm{R}$ receptor mice, transgenic for the LacZ gene located between two Lox-P sites, showing presence of $\beta$-gal positive purkinje neurons, cardiomyocytes and hepatocytes in all injected animals, proving that contribution of Crerecombinase positive cells to these cell lineages is at least in part due to fusion with host cells. Yet another study showed that myofibers were derived from fusion between mature myeloid cells and muscle fibers in response to injury and not through a myogenic stem cell intermediate ${ }^{33}$ even though other studies did not confirm this to be the sole mechanism of muscle repair. ${ }^{32}$ The phenomenon of cell fusion both in vitro and in vivo appears to be rare $(1 / 100,000$ cells), and seems to occur most readily in cells where polyploidy is commonly seen, including hepatocytes, skeletal muscle, cardiac muscle and purkinje cells. In most cases fusion 
likely does not occur between the HSC itself and the target cell, but may be caused by fusion of a descendant of HSC, such as monocytes, with the target cell. In some respects, this also qualifies as plasticity, as generally, genetic information present in the donor cell is partially effaced, as is the genetic information from the host cell to which the cell fuses. However, if this were caused by fusion of monocytes with tissue specific cells, this would not qualify as "stem cell" plasticity.

\section{Conclusion}

Irrespective of the mechanism underlying stem cell plasticity, many believe that adult stem cells hold considerable clinical potential. Some of the potentials and challenges of adult stem cell use in therapy are outlines in box 2 .

Box 2. Potential of adult stem cells

- treatment of degenerative disorders of many organs

- allows autologous transplantation thereby reducing immune rejection

- ex vivo gene correction of autologous stem cells in case of genetic disorders Challenges to overcome

- confirm greater potential of adult stem plasticity by independent groups

- provide evidence that undifferentiated adult stem cells will not cause tumor

- types of cells to transplant, differentiated vs. undifferentiated cells

- homing of adult stem cells to the site of injury/engraftment

- immune rejection in case of genetically corrected allogeneic cells

HSC are extensively used for transplants in blood related disorders and, if its newfound plasticity can be further validated, this could be extended to other disorders as well. MSC are already being used clinically and could be a source of cells to treat bone and muscle diseases. If isolation and propagation of the more pluripotent stem cells such as mesangioblasts, SKPs, or MAPCs can be improved, they may serve as a source of cells to treat neural, mesenchymal and even epithelial disorders. While all these cells hold immense therapeutic potential, there remains a long road ahead in which investigators will need to learn more about the cells them selves, possible mechanisms underlying in vivo observations and long-term effects of such cells used in vivo.

\section{References}

1. Petersen BE, Bowen WC, Patrene KD, et al. Bone marrow as a potential source of hepatic oval cells. Science 1999;284: 1168-70.

2. Bjornson CRR, Rietze RL, Reynolds BA, Magli MC, Vescovi AL. Turning brain into blood: a hemotopoeitic fate adopted by adult neural stem cells in vivo. Science 1999;283:534-7.

3. Raff M. Adult stem cell plasticity: fact or artifact. Annu Rev Cel Dev Biol 2003;19:1-22.

4. Verfaillie CM, Pera MF, Lansdorp PM. Stem cells: hype and reality. Hematology (Am Soc Hematol Educ Program) 2002:369-91.

5. Joshi CV, Enver T. Plasticity revisited. Curr Opin Curr Biol 2002;14:749-55.

6. Holden C, Vogel G. Stem cells. Plasticity: time for a reappraisal? Science 2002;296:2126-9.

7. Hawley RG, Sobieski DA. Somatic stem cell plasticity: to be or not to be. Stem Cells 2002;20:195-7.

8. Kornack DR, Rakie P. Cell proliferation without neogenesis in adult primate neocortex. Science 2001;294:2127-30.

9. Herzog EL, Chai L, Krause DS. Plasticity of marrow-derived stem cells. Blood 2003;102:3483-93.

10. Conget PA, Minguell JJ. Phenotypical and functional properties of human bone marrow mesenchymal progenitor cells. J Cell Physiol 1999;181:67-73.

11. Zuk PA, Zhu M, Ashjian P, et al. Human adipose tissue is a source of multipotent stem cells. Mol Biol Cell 2002;13: 4279-95.

12. in 't Anker PS, Noort WA, Scherjon SA, et al. Mesenchymal stem cells in human second-trimester bone marrow, liver, lung, and spleen exhibit a similar immunophenotype but a heterogeneous multilineage differentiation potential. Haematologica 2003;88:847-52.

13. Devine SM, Cobbs $C$, Jennings $M$, Bartholomew A, Hoffman R. Mesenchymal stem cells distribute to a wide range of tissues following systemic infusion into nonhuman primates. Blood 2003;101:2999-30001.

14. Pelosi E, Valtieri $M$, Coppola $S$, et al. Identification of hemangioblast in postnatal life. Blood 2002;100:3202-8.

15. Grant MB, May WS, Cabellero S, et al. Adult hematopoietic stem cells provide hemangioblast activity during retinal neovascularization. Nat Med 2002;8:607-12.

16. Forrai A, Robb L. The hemangioblast - between blood and vessels. Cell Cycle 2003;2:86-90.

17. Bailey AS, Fleming WH. Converging roads: evidence for an adult hemangioblast. Exp Hematol 2003;31:987-93.

18. Bailey AS, Jiang $S$, Afentoulis $M$, et al. Transplanted adult hematopoietic stem cells differentiate into functional endothelial cells. Blood 2004;103:13-9.

19. Reyes M, Lund T, Lenvik T, Aguiar A, Koodie L, Verfaillie CM. Purification and ex vivo expansion of postnatal human marrow mesodermal progenitor cells. Blood 2001;98: 2615-25.

20. Jiang $Y$, Jahagirdar BN, Reinhardt RL, et al. Pluripotency of mesenchymal stem cells derived from bone marrow. Nature 2002;418:41-9.

21. Muguruma $Y$, Reyes $M$, Nakamura $Y$, et al. In vivo and in vitro differentiation of myocytes from human bone marrow-derived multipotent progenitor cells. Exp Hematol 2003;31:1323-30.

22. Bruder SP, Jaiswal N, Haynesworth SE. Growth kinetics, self-renewal, and the osteogenic potential of purified human mesenchymal stem cells during extensive subcultivation and following cryopreservation. J Cell Biochem 1997;64:278-94. 
23. Pittenger MF, Mackay AM, Beck SC, et al. Multilineage potential of adult mesenchymal stem cells. Science 1999;284:143-7.

24. Gronthos S, Zannettino ACW, Hay SJ, et al. Molecular and cellular characterization of highly purified stromal stem cells derived from human bone marrow. J Cell Sci 2003;116:1827-35.

25. Mackenzie TC, Flake AW. Multilineage differentiation of human MSC after in utero transplantation. Cytotherapy 2001;3:403-5.

26. Noel D, Djouad F, Jorgense C. Regenerative medicine through mesenchymal stem cells for bone and cartilage repair. Curr Opin Investig Drugs 2002;3:1000-4.

27. Quintavallla J, Uziel-Fusi S, Yin J, et al. Fluorescence labeled mesenchymal stem cells (MSCs) maintains multilineage potential and can be detected following implantation into articular cartilage defects. Biomaterials 2002;23: 109-19.

28. Olmsted-Davis EA, Gugala Z, Camargo F, et al. Primitive adult hematopoeitic stem cells can function as osteoblast precursors. Proc Natl Acad Sci USA 2003;100:15877-82.

29. Cossu G, Bianco P. Mesoangioblasts-vascular progenitors for extravascular mesodermal tissues. Curr Opin Gen Dev 2003;13:537-42.

30. Ferrari G, Cusella-De Angelis MG, Coletta G, et al. Muscle regeneration by bone marrow-derived myogenic progenitors. Science 1998;279:1528-30.

31. Gussoni E, Soneoka CD, Buzney EA, et al. Dystrophin expression in the $\mathrm{mdx}$ mouse restored by stem cell transplantation. Nature 1999;401:390-4.

32. LaBarge MA, Blau HM. Biological progression from adult bone marrow to mononucleate muscle fiber in response to injury. Cell 2002;111:589-601.

33. Camargo FD, Green R, Capetenaki Y, Jackson KA, Goodell MA. Single hematopoietic stem cells generate skeletal muscle through myeloid intermediates. Nat Med 2003;9: 1520-7.

34. Wakitani S, Saito T, Caplan Al. Myogenic cells derived from rat bone marrow mesenchymal stromal cells exposed to 5azacytidine. Muscle Nerve 1995;18:1417-26.

35. Sampaolesi M, Torrente $Y$, Innocenzi A, et al. Cell therapy of alpha-sarcoglycan null dystrophic mice through intraarterial delivery of mesoangioblasts. Science 2003;301: 487-92.

36. Bittner RE, Schofer C, Weipoltshammer K, et al. Recruitment of bone-marrow-derived cells by skeletal and cardiac muscle in adult dystrophic mdx mice. Anat Embryol (Berl) 1999;199:391-6.

37. Wang JS, Shum-Tim D, Chedrawy E, Chiu RC. The coronary delivery of marrow stromal cells for myocardial regeneration: pathophysiologic and therapeutic implications. J Thor Cardiovas Sur 2001;122:699-705.

38. Toma C, Pittenger MF, Cahill KS, Byrne BJ, Kessler PD. Human mesenchymal stem cells differentiate to a cardiomyocyte phenotype in the adult murine heart. Circulation 2002;105:93-8.

39. Liechty KW, Mackenzie TC, Shaaban AF, et al. Human mesenchymal cells engraft and demonstrate site-specific differentiation after in utero transplantation in sheep. Nat Med 2000;6:1282-6.

40. Tomita S, Li RK, Weisel RD, Mickle DA, Kim EJ, Sakai T, et al. Autologous transplantation of bone marrow cells improve damaged heart function. Circulation 1999;100: 247-56.

41. Orlic D, Kajstura J, Chimenti S, Bodine DM, Leri A, Anversa $P$. Transplanted adult bone marrow cells repair myocardial infarcts in mice. Ann NY Acad Sci 2001;938:221-9.
42. Orlic D, Kajstura J, Chimenti S, et al. Mobilized bone marrow cells repair the infracted heart improving function and survival. Proc Natl Acad Sci USA 2001;98:10344-9.

43. Jackson KA, Mahka SM, Wang $\mathrm{H}$, et al. Regeneration of ischemic cardiac muscle and vascular endothelium by adult stem cells. J Clin Invest 2001;107:1395-402.

44. Rubart M, Pasumarthi KB, Nakajima H, Soonpaa MH, Nakajima HO, Field LJ. Physiological coupling of donor and host cardiomyocytes after cellular transplantation. Circ Res 2003;13:1176-8.

45. Zandstra PW, Bauwens C, Yin T, et al. Scalable production of embryonic stem cell-derived cardiomyocytes. Tissue Eng 2003;9:767-78.

46. Makino S, Fukuda K, Miyoshi S, et al. Cardiomyocytes can be generated from marrow stromal cells in vitro. $J$ Clin Invest 1999;103:697-705.

47. Crosby JR, Kaminski WE, Schatteman G, et al. Endothelial cells of hematopoeitic origin makes a significant contribution to adult blood vessel formation. Circ Res 2000;87: 728-30.

48. Hirschi KK, Goodell MA. Hematopoeitic, vascular and cardiac fates of bone marrow-derived cells. Gene Ther 2002;9:648-52.

49. Gulati R, Jevremovic D, Peterson TE, et al. Diverse origin and function of cells with endothelial phenotype obtained from adult human blood. Cir Res 2003;93:1023-5.

50. Wood HB, May G, Healy L, Enver T, Morriss-Kay GM. CD34 expression patterns during early mouse development are related to modes of blood vessel formation and reveal additional sites of hematopoiesis. Blood 1997;90:2300-11.

51. Fehling HJ, Lacaud G, Kubo A, et al. Tracking mesoderm induction and its specification to the hemangioblast during embryonic stem cell differentiation. Development 2003; 130:4217-27.

52. Kocher AA, Schuster MD, Szabolcs MJ, et al. Neovascularization of ischemic myocardium by human bone marrowderived angioblasts prevents cardiomyocyte apoptosis, reduces remodeling and improves cardiac function. Nat Med 2001;7:430-6.

53. Cogle CR, Wainman DA, Jorgensen ML, Guthrie SM, Mames RN, Scott EW. Adult human hematopoeitic cells provide functional hemangioblast activity. Blood 2004;103:133-5.

54. Eglitis MA, Mezey E. Hematopoeitic cells differentiate into both microglia and macroglia in the brains of adult mice. Proc Natl Acad Sci USA 1997;94:4080-5.

55. Brazelton TR, Rossi FM, Keshet GI, Blau HM. From marrow to brain: expression of neuronal phenotypes in adult mice. Science 2000;290:1775-9.

56. Priller J, Persons DA, Klett FF, Kempermann G, Kreutzberg GW. Neogenesis of cerebellar Purkinje neurons from genemarked bone marrow cells in vivo. J Cell Biol 2001;155: 733-8.

57. Priller J, Flugel A, Wehner T, et al. Targeting gene-modified hematopoietic cells to the central nervous system: use of green fluorescent protein uncovers microglial engraftment. Nat Med 2001;7:1356-61.

58. Koshizuka S, Okada S, Okawa A, et al. Transplanted hematopoeitic stem cells from bone marrow differentiate into neural lineage cells and promotes functional recovery after spinal cord injury in mice. J Neuropathol Exp Neurol 2004;63:672-4.

59. Mezey E, Chandross KJ, Harta G, Maki RA, McKercher SR. Turning blood into brain: cells bearing neuronal antigens generated in vivo from bone marrow. Science 2000;290: 1779-82.

60. Mezey E, Key S, Vogelsang G, Szalayova I, Lange GD, Crain B. Transplanted bone marrow generated new neurons 
in human brains. Proc Natl Acad Sci USA 2003;100: 1364-9.

61. Castro RF, Jackson KA, Goodell MA, et al. Failure of bone marrow cells to transdifferentiate into neural cells in vivo. Science 2002;297:1299.

62. Wagers AJ, Sherwood RI, Christensen JL, Weissman IL. Little evidence for developmental plasticity of adult hematopoeitic stem cells. Science 2002;297:2256-9.

63. Woodbury D, Schwarz EJ, Prockop DJ, Black IB. Adult rat and human bone marrow stromal cell differentiate into neurons. J Neurosci Res 2000;15:364-70.

64. Kopen GC, Prockop DJ, Phiney DG. Marrow stromal cells migrate throughout forebrain and cerebellum, and they differentiate into astrocytes after injection into neonatal mouse brains. Proc Natl Acad Sci USA 1999;96:10711-6.

65. Akiyama Y, Radtke C, Honmou O, Kocsos JD. Remyelination of the spinal cord following intravenous delivery of bone marrow cells. Glia 2002;39:229-36.

66. Akiyama Y, Radtke C, Kocsi JD. Remyelination of the rat spinal cord by transplantation of identified bone marrow stromal cells. J Neurosci 2002;22:6623-30.

67. Jin HK, Carter JE, Huntley GW, Schuchman EH. Intracerebral transplantation of mesenchymal stem cells into acid sphingomyelinase-deficient mice delays the onset of neurological abnormalities and extends their life span. J Clin Invest 2002;109:1183-91.

68. Jiang $\mathrm{Y}$, Henderson D, Blackstad $M$, Chen A, Miller RF, Verfaillie CM. Neuroectodermal differentiation from mouse multipotent adult progenitor cells. Proc Natl Acad Sci USA 2003;100:11854-60.

69. Krause DS, Theise ND, Collector MI, et al. Multi-organ, multi-lineage engraftment by a single bone marrow derived stem cell. Cell 2001;105:369-77.

70. Petersen BE. Hepatic "stem cells" coming full circle. Blood Cells Mol Dis 2001;27:590-600.

71. Theise ND, Badve S, Saxena R, et al. Derivation of hepatocytes from bone marrow cells in mice after radiation-induced myeloablation. Hepatology 2000;31:235-40.

72. Wang X, Foster $M$, Al-Dhalimy $M$, Lagasse E, Finegold $M$, Grompe $M$. The origin and liver repopulating capacity of murine oval cells. Proc Natl Acad Sci USA 2003;100(Suppl 1): 11881-8.

73. Lagasse E, Connors H, Al-Dhalimy M, et al. Purified hematopoietic stem cells can differentiate into hepatocytes in vivo. Nat Med 2000;6:1229-34.

74. Grompe $M$. The role of bone marrow stem cells in liver regeneration. Semin Liver Dis 2003;23:363-72.

75. Korbling $M$, Katz Rl, Khanna A, et al. Hepatocytes and epithelial cells of donor origin in recipients of peripheral blood stem cells. New Engl J Med 2002;346:738-46.

76. Theise ND, Nimmakayalu M, Gardner R, et al. Liver from bone marrow in humans. Hepatology 2000;32:11-6.

77. Danet GH, Luongo JL, Butler G, et al. C1qRp defines a new human stem cell population with hematopoeitic and hepatic potential. Proc Natl Acad Sci USA 2002;99: 10441-5.

78. Schwartz RE, Reyes M, Koodie L, et al. Multipotent adult progenitor cells from bone marrow differentiate into functional hepatocyte-like cells. J Clin Invest 2002;109: 1291-302.

79. Ianus A, Holz GG, Theise ND, Hussain MA. In vivo derivation of glucose-competent pancreatic endocrine cells from bone marrow without evidence of cell fusion. J Clin Invest 2003; 111:843-50.

80. Hess D, Li L, Martin M, et al. Bone marrow-derived stem cells initiate pancreatic regeneration. Nat Biotechnol 2003;21:763-70.
81. Johansson CB, Momma S, Clarke DI, Risling $M$, Lendahl U, Frisen J. Identification of a neural stem cell in the adult mammalian central nervous system. Cell 1999;96: 25-34.

82. Doetsch F, Caille L, Lim DA, Carcia-Verdugo JM, AlvarezBuylla A. Subventricular zone astrocytes are neural stem cells in the adult mammalian brain. Cell 1999;97: 703-16.

83. Rietze RL, Valcanis H, Brooker GF, Thomas T, Voss AK, Bartlett PF. Purification of a pluripotent neural stem cell from the adult mouse brain. Nature 2001;412:7369.

84. Morshead CM, Benvensite P, Iscove NN, Van der Kooy D. Hematopoieitc competence is a rare property of neural stem cells that may depend on genetic and epigenetic alterations. Nat Med 2002;8:268-73.

85. Galli R, Borello U, Gritti A, et al. Skeletal myogenic potential of human and mouse neural stem cells. Nat Neurosci 2000;3:986-91.

86. Tsai RY, McKay RD. Cell contact regulates fate choice by cortical stem cells. J Neurosci 2000;20:3725-3725.

87. Clarke Dl, Johansson CB, Wilbertz J. Generalized potential of adult neural stem cells. Science 2000;288:1660-3.

88. Gambardella L, Barrandon Y. The multifaceted adult epidermal stem cell. Curr Opin Cell Biol 2003;15:771-7.

89. Taylor G, Lehrer MS, Jensen PJ, Sun TT, Lavker RM. Involvement of follicular stem cells in forming not only the follicle but also the epidermis. Cell 2000;102:451-61.

90. Oshima H, Rochat A, Kedzia C, Kobayashi K, Barrandon Y. Morphogenesis and renewal of hair follicles from adult multipotent stem cells. Cell 2001;104:233-45.

91. Dunnwald M, Tomanek-Chalkley A, Alexandrunas D, et al. Isolation of a pure population of epidermis stem cell for use in tissue engineering. Exp Dermatol 2001;10:45-54.

92. Liang L, Bickenbach JR. Somatic epidermal cells can produce multiple cell lineages during development. Stem Cells 2002;20:21-31.

93. Toma JG, Akhavan M, Fernandes KJL, et al. Isolation of multipotent adult stem cells from the dermis of mammalian skin. Nat Cell Biol 2001;3:778-84.

94. Mauro A. Satellite cells of skeletal muscle fibers. J Biophys Biochem Cytol 1961;9:493-5.

95. Beauchamp JR, Heslop L, Yu DS, et al. Expression of CD 34 and myf 5 defines the majority of quiescent adult skeletal muscle satellite cells. J Cell Biol 2000;151:1221-34.

96. Seale $P$, Rudnicki MA. A new look at the origin, function and "stem-cell" status of muscle satellite cells. Dev Biol 2000;218:115-24.

97. Beauchamp JR, Morgan JE, Pagel CN, Partridge TA. Dynamics of myoblast transplantation reveal a discrete minority of precursors with stem cell-like properties as the myogenic source. J Cell Biol 1999;144:1113-22.

98. Seale P, Sabourin LA, Girgis-Gabardo A, Mansouri A, Gruss $\mathrm{P}$, Rudnicki MA. Pax7 is required for the specification of myogenic satellite cells. Cell 2000;102:777-86.

99. Torrente $\mathrm{Y}$, Tremblay JP, Pisati F, et al. Intraarterial injection of muscle-derived CD34 (+) Sca-1 (+) stem cells restores dystrophin in mdx mice. J Cell Biol 2001;152: $335-48$.

100. Asakura A, Seale P, Girgis-Gabardo A, Rudnicki MA Myogenic specification of side population cell sin skeletal muscle. J Cell Biol 2002;159:123-34.

101. Jackson KA, Mi T, Goodell MA. Hematopoeitic potential of stem cells isolated from murine skeletal muscle. Proc Natl Acad Sci USA 1999;96:14482-6.

102. Brockes JP. Amphibian limb regeneration: rebuilding a complex structure. Science 1997;276:81-7. 
103. Wilmut I, Schnieke AE, McWhir J, Kind AJ, Campbell KH. Viable offspring derived from fetal and adult mammalian cells. Nature 1997;385:810-3.

104. Bussard AE, Pages J. Establishment of a permanent hybridoma producing a mouse autoantibody. Prog Clin Biol Res 1978;26:167-79.
105. Ying QL, Nichols J, Evans EP, Smith AG. Changing potency by spontaneous fusion. Nature 2002;416:5458.

106. Terada N, Hamazaki T, Oka M, et al. Bone marrow cells adopt phenotypes of other cells by spontaneous cell fusion. Nature 2002;416:542-5.

Available online at www.sciencedirect.com

Science $\mathcal{O}^{\text {DiRect }}{ }^{\circledR}$ 